\title{
THERMODYNAMIC INVESTIGATION ON SOLID DISPERSIONS OF NICOTINAMIDE - SULPHAMERAZINE DRUG SYSTEM
}

\author{
H. Shekhar* and Vishnu Kant* \\ *Department of Chemistry, V.K.S.University, Ara-802301, India.
}

\begin{abstract}
Nicotinamide (NA) and Sulphamerazine (SM) have been in orally use of a number of diseases for last few decades. Nicotinamide is shown as HIV, M. tuberculosis and Pellagra preventive agent while sulphamerazine is used in diarrhea, dysentery, E.coli etc. In recent years, research on solid dispersions of binary drug products is playing a significant role in drug delivery process of the pharmaceutical industries. The present study highlights the thermodynamic characteristics of solid dispersions binary products of active pharmaceutical ingredient SM with pharmaceutical excipient NA. The solid-liquid equilibrium data of NA-SM system favors the formation of a eutectic (E) solid dispersions at 0.056 mole fraction of SM and non eutectic solid dispersions (A1-A8) at their defined compositions and temperatures. In order to illustrate the molecular interaction, the activity co-efficient model based on enthalpy of fusion is employed to calculate the excess partial and integral thermodynamic functions such as $\mathrm{g}^{\mathrm{E}}, \mathrm{h}^{\mathrm{E}}$ and $\mathrm{s}^{\mathrm{E}}$. The positive value of excess Gibbs free energy predicts the stronger molecular interaction between the like molecules as compared to unlike molecules. The spontaneity of mixing of eutectic and non eutectic solid dispersions has been discussed by the integral mixing quantities $\Delta \mathrm{G}^{\mathrm{M}}, \Delta \mathrm{H}^{\mathrm{M}}$ and $\Delta \mathrm{S}^{\mathrm{M}}$. The critical radius ( $\mathrm{r}^{*}$ ) has been found in $n m$ scale which suggests about the solidification technique to find the nano solid dispersion and remains very surprising for the pharma world. The binary interface structure of solid dispersions has been discussed in the light of Jackson model of interface structure.
\end{abstract}

Keywords: Solid-liquid equilibrium data; thermodynamic excess and mixing functions, critical radius; interfacial energy; roughness parameter.

\section{INTRODUCTION}

Heterocycles are important biological and pharmacological active chemical entities. The research and development on this class of compounds have provided myriad applications in medicines and food production over past few decades. Nicotinamide (NA) is a structural component of adenine dinucleotide (NAD) and adenine dinucleotide phosphate (NADP) which have very important co-enzymic role in metabolic oxidationreduction reactions in human being. It is water soluble vitamin $\mathrm{B}_{3}$ and a part of vitamin B-complex. It is anti $\mathrm{HIV}^{1}$, anti M. tuberculosis ${ }^{2}$, anti inflammatory ${ }^{3}$ and anti Pellagra ${ }^{4}$ agents. Sulphamerazine (SM) is an antibacterial agent. It is a sulphonamide bacteriostatic antibiotic ${ }^{5}$. It is most often used as part of a synergistic combination with trimethoprim. Its primary activity is against susceptible forms of Streptococcus, Staphylococcus aureus, Escherichia coli, Haemophilus influenzae ${ }^{6}$, and oral anaerobes. Eutectic and non-eutectic solid dispersions 7,8 of active pharmaceutical hydrophobic ingredients (APIs) with hydrophilic excipient Nicotinamide (NA) are important not only because of the ability to control pharmaceutical properties without changing covalent bonds but also they can be used in the design ${ }^{9}$ of new materials. In recent years, advances in supramolecular engineering and chemistry have motivated to extend research on the design of pharmaceutical materials by directing molecular association of different components in the crystalline state to form binary/ternary solid dispersions of potential interest. Pharmaceutical properties of some binary solid dispersion have also been reported ${ }^{10,11}$ by their enhanced solubility, dissolution rate, hygroscopicity, and chemical stability. Eutectic mixture formation between nicotinamide and hydrophobic carriers/drugs of different therapeutic classes was also investigated ${ }^{12,13}$ recently to reduce the drug particle size, and increases the dissolution rate and thus changes the biopharmaceutical properties. in view of pharmacological importance, Nicotinamide (NA)-Sulphamerazine (SM) drug system was selected for their thermodynamic investigations such as solidliquid equilibrium, thermodynamic excess and mixing quantities, solid-liquid interfacial energy, critical radius, volume free energy change during solidification and interfacial structure of eutectic and non-eutectic solid dispersions.

Author for Correspondence: H. Shekhar Department of Chemistry, V.K.S.University, Ara-802301, India. Email: hshe2503@rediffmail.com, imvishnukant@gmail. com. 


\section{EXPERIMENTAL}

Nicotinamide (NA) (Thomos Baker, India) and Sulphamerazine (SM) (Chempure, India) were directly taken for investigation. The melting point of nicotinamide was found to be $128^{\circ} \mathrm{C}$ while for sulphamerazine $236^{\circ} \mathrm{C}$, respectively. For measuring the solid-liquid equilibrium data of NA-SM system, mixtures of different compositions were made in glass test tubes by repeated heating followed by chilling in ice and their melting temperatures were determined by the thaw-melt method ${ }^{14,15}$. The melting and thaw temperatures were determined in a Toshniwal melting point apparatus using a precision thermometer which could read correctly up to $\pm 0.1^{\circ} \mathrm{C}$. The heater was regulated to give above $1{ }^{\circ} \mathrm{C}$ increase in temperature in every five minutes. Heat of fusion of materials measured by the DTA method ${ }^{16,17}$ was used to evaluate the various thermodynamic parameters.

\section{RESULT AND DISCUSSION}

\section{Solid - Liquid Equilibrium (SLE) Study}

The SLE data of NA-SM system determined by the thaw melt method is reported in Table 1. The system shows the formation of an eutectic ${ }^{18}$. The melting point of NA $\left(128^{\circ} \mathrm{C}\right)$ decreases on the addition of second component SM (M.P., $236^{\circ} \mathrm{C}$ ) and further attains minimum and then increases. Eutectic E (0.056 mole fraction of SM) as well as non-eutectic solid dispersions (A1-A8) has been obtained at the compositions and temperatures are shown in Table 1. At the eutectic temperature two phases namely a liquid phase and two solid phases are in equilibrium and the system is invariant. The homogenous binary liquid solution exists in the region above the eutectic temperature while the two solid phases exists in the region below the eutectic temperature. The region located below the liquidus line on the left side a binary liquid and solid NA exist while in a similar region located on the right side a binary liquid and solid SM system co-exist.

\section{Thermodynamic Study}

The values of heats of fusion of eutectic and noneutectic alloys are calculated by the mixture law. The value of heat of fusion of binary solid dispersions A1-A8, E is given in Table 1 . The activity coefficient and activity of components for the systems under investigation has been calculated from the equation ${ }^{19}$ given below

$$
-\ln \chi_{\mathrm{i}} \gamma_{i}=\frac{\Delta H_{i}}{R}\left(\frac{1}{T_{e}}-\frac{1}{T_{i}}\right)
$$

where $\gamma_{i}$ is activity coefficient of the component $\mathrm{i}$ in the liquid phase respectively, $\Delta \mathrm{H}_{\mathrm{i}}$ is the heat of fusion of component $\mathrm{i}$ at melting point $\mathrm{Ti}$ and $\mathrm{R}$ is the gas constant. $\mathrm{T}_{e}$ is the melting temperature of alloy. Using the values of activity and activity coefficient of the components in binary solid dispersions mixing and excess thermodynamics functions have been computed.

\section{Mixing Functions}

In order to know the mixing characteristics of components in the binary melt, Integral molar free energy of mixing $\left(\Delta \mathrm{G}^{\mathrm{M}}\right)$, molar entropy of mixing $\left(\Delta \mathrm{S}^{\mathrm{M}}\right)$ and molar enthalpy of mixing $\left(\Delta \mathrm{H}^{\mathrm{M}}\right)$ and partial thermodynamic mixing functions of the binary solid dispersions were determined by using the following equations

$$
\begin{aligned}
& \Delta \mathrm{G}^{\mathrm{M}}=\mathrm{RT}\left(\chi_{\mathrm{NA}} \ln \mathrm{N}_{\mathrm{NA}}+\chi \mathrm{SM} \ln \mathrm{S}_{\mathrm{SM}}\right) \\
& \Delta \mathrm{S}^{\mathrm{M}}=-\mathrm{R}\left(\gamma_{\mathrm{NA}} \ln \chi_{\mathrm{NA}}+\chi_{\mathrm{SM}} \ln \chi_{\mathrm{SM}}\right) \\
& \Delta \mathrm{H}^{\mathrm{M}}=\mathrm{RT}\left(\chi_{\mathrm{NA}} \ln \gamma_{\mathrm{NA}}+\gamma_{\mathrm{SM}} \ln \gamma_{\mathrm{SM}}\right) \\
& \mathrm{G}_{-\mathrm{i}}^{\mathrm{M}}=\mu-_{\mathrm{i}}^{\mathrm{M}}=\mathrm{RT} \ln \mathrm{a}_{\mathrm{i}}
\end{aligned}
$$

where $\mathrm{G}^{-} \mathrm{i}^{\mathrm{M}}\left(\mu^{-} \mathrm{i}^{\mathrm{M}}\right)$ is the partial molar free energy of mixing of component $i$ (mixing chemical potential)in binary mix and $\square_{\mathrm{i}}$ and $\mathrm{a}_{\mathrm{i}}$ is the activity coefficient and activity of component respectively. The positive value ${ }^{20}$ of Gibbs free energy of mixing for solid dispersions A5-A8 (Table 2) suggests that the mixing in all cases is non-spontaneous and the negative value of $\Delta \mathrm{G}^{\mathrm{M}}$ for $\mathrm{E}$ and A1-A4 favours the spontaneous mixing of the components. The integral molar enthalpy of mixing value corresponds to the value of excess integral molar free energy of the system favors the regular behaviour in the binary solutions.

\section{Excess Functions}

In order to unfold the nature of the interactions between the components forming the eutectic and non-eutectic solid dispersions, the excess thermodynamic functions such as integral excess integral excess free energy $(\mathrm{g} E)$, excess integral entropy $\left({ }^{\mathrm{E}}\right.$ ) and excess integral enthalpy $\left(h^{E}\right)$ were calculated using the following equations;

$$
\begin{aligned}
& \sum x_{i} d z_{i}^{-M}=0 \\
& \text { or } \chi_{N A} d H_{N A}^{-M}+\chi_{S M} d H_{S M}^{-M}=0 \\
& \text { or } d H_{N A}^{-M}=\frac{\chi_{S M}}{\chi_{N A}} d H_{S M}^{-M}
\end{aligned}
$$

and excess chemical potential or excess partial free energy of mixing

The values of $\square \ln \square$ / $/ \square$ Tcan be determined by the slope of liquidus curve near the binary mix form in the phase diagram. The values of the excess thermodynamic functions are given in Table 3. The value of the excess free energy is a measure of the departure of the system from ideal behavior. The reported excess thermodynamic data substantiate the earlier conclusion of an appreciable interaction between the parent components during the formation of solid dispersions. The positive $\mathrm{g}^{\mathrm{E}}$ value $^{21}$ for all eutectic and non-eutectic solid dispersions infers stronger interaction between like molecules in binary dispersions. The excess entropy is a measure of the change in configurational energy due to a change in potential energy and indicates an increase in randomness. 
Table 1: Phase composition, melting temperature, heat of fusion $(\Delta \mathbf{H})$, roughness parameter $(\alpha)$, values of entropy of fusion per unit volume ( $\left.\Delta \mathbf{S}_{v}\right)$, interfacial energy $(\sigma)$, grain boundary energy $\left(\sigma_{\mathrm{gb}}\right)$ and Gibbs-Thomson coefficient $(\tau)$

\begin{tabular}{|c|c|c|c|c|c|c|c|c|c|c|c|}
\hline Alloy & $\mathbf{X}_{\mathrm{NA}}$ & $\mathbf{X}_{\mathrm{SM}}$ & MP & $\underset{(\mathrm{J} / \mathrm{mol})}{\Delta \mathbf{H}}$ & $\begin{array}{c}\Delta \mathrm{S}(\mathrm{J} / \\
\mathrm{mol} / \mathbf{K})\end{array}$ & $\alpha$ & $\begin{array}{c}\sigma \times 10^{2} \\
\left(\mathrm{Jm}^{-2}\right)\end{array}$ & $\begin{array}{c}\sigma_{\mathrm{gb}} \times 10^{2} \\
\left(\mathrm{Jm}^{-2}\right)\end{array}$ & $\underset{\left(\mathrm{kJK}^{-1} \mathbf{m}^{-3}\right)}{\Delta \mathbf{S}_{\mathrm{s}}}$ & $\underset{\left(\mathrm{Jcm}^{-3}\right)}{\Delta \mathbf{H}_{\mathrm{v}}}$ & $\begin{array}{c}\tau \times 10^{-05} \\
(\mathrm{Km})\end{array}$ \\
\hline $\mathrm{A} 1$ & 0.975 & 0.025 & 127.0 & 25732.5 & 64.331 & 7.74 & 5.02 & 9.70 & 718 & 287.04 & 1.35 \\
\hline E & 0.944 & 0.056 & 125.9 & 26144.8 & 65.542 & 7.88 & 4.99 & 9.64 & 708 & 282.23 & 1.36 \\
\hline A2 & 0.935 & 0.065 & 130.5 & 26264.5 & 65.092 & 7.83 & 4.98 & 9.62 & 696 & 280.89 & 1.38 \\
\hline A3 & 0.885 & 0.115 & 140.0 & 26929.5 & 65.205 & 7.84 & 4.94 & 9.54 & 663 & 273.87 & 1.44 \\
\hline A4 & 0.855 & 0.145 & 143.3 & 27328.5 & 65.646 & 7.90 & 4.92 & 9.50 & 649 & 269.99 & 1.46 \\
\hline A5 & 0.720 & 0.280 & 176.0 & 29124.0 & 64.864 & 7.80 & 4.83 & 9.34 & 568 & 254.93 & 1.64 \\
\hline A6 & 0.530 & 0.470 & 195.0 & 31651.0 & 67.630 & 8.13 & 4.76 & 9.19 & 510 & 238.75 & 1.80 \\
\hline A7 & 0.455 & 0.545 & 211.0 & 32648.5 & 67.456 & 8.11 & 4.74 & 9.15 & 483 & 233.53 & 1.90 \\
\hline A8 & 0.190 & 0.810 & 222.0 & 36173.0 & 73.077 & 8.79 & 4.69 & 9.06 & 442 & 218.75 & 2.05 \\
\hline NA & & & 128.0 & & & 7.62 & 5.05 & 9.75 & 726 & 291.17 & 1.34 \\
\hline SM & & & 236.3 & & & 9.14 & 4.68 & 9.04 & 414 & 210.68 & 2.19 \\
\hline
\end{tabular}

Table 2: Value of partial and integral mixing of Gibbs free energy $\left(\Delta \mathbf{G}^{\mathrm{M}}\right)$, enthalpy $\left(\Delta \mathbf{H}^{\mathrm{M}}\right)$ and entropy $\left(\Delta \mathbf{S}^{\mathrm{M}}\right)$ of NA-SM system

\begin{tabular}{|c|c|c|c|c|c|c|c|c|c|}
\hline Alloy & $\Delta \mathbf{G}_{\substack{\mathrm{Na} \\
\mathrm{J} / \mathrm{mol}}}{ }^{-\mathbf{M}}$ & $\underset{\mathrm{J} / \mathrm{mol}}{\Delta \mathbf{G}_{\mathrm{SM}}{ }^{-\mathrm{M}}}$ & $\begin{array}{l}\Delta \mathbf{G}^{\mathrm{M}} \\
\mathrm{J} / \mathrm{mol}\end{array}$ & $\underset{\substack{\mathrm{J} / \mathrm{mol} \\
\Delta \mathbf{H}^{-\mathrm{M}}}}{{ }^{-1}}$ & $\underset{\mathrm{J} / \mathrm{mol}}{\Delta \mathbf{H}_{\mathrm{SM}}{ }^{-\mathrm{M}}}$ & $\begin{array}{c}\Delta \Delta \mathbf{H}^{\mathrm{M}} \\
\mathrm{J} / \mathrm{mol}\end{array}$ & $\underset{\substack{\mathrm{J} / \mathrm{mol} / \mathrm{K} \\
\Delta \mathrm{S}^{-\mathrm{M}}}}{\Delta}$ & $\underset{\mathrm{J} / \mathrm{mo} / \mathrm{K}}{\Delta \mathrm{S}_{\mathrm{SM}}{ }^{-\mathrm{M}}}$ & $\begin{array}{c}\Delta \Delta \mathbf{S}^{\mathrm{M}} \\
\mathrm{J} / \mathrm{mol} / \mathbf{K}\end{array}$ \\
\hline A1 & -63.342 & -8305.34 & -269.392 & 20.855 & 3962.4 & -119.394 & 0.21 & 30.669 & 0.972 \\
\hline E & -133.02 & -8388.93 & -595.348 & 58.107 & 1170.43 & -120.397 & 0.479 & 23.964 & 1.7943 \\
\hline A2 & 158.35 & -8039.39 & -374.499 & 383.82 & 1130.24 & -432.337 & 0.559 & 22.725 & 1.9996 \\
\hline A3 & 760.1 & -7317.51 & -168.826 & 1179.6 & 108.933 & -1056.46 & 1.016 & 17.982 & 2.9668 \\
\hline A4 & 969.13 & -7066.76 & -196.076 & 1511.3 & -383.265 & -1236.61 & 1.302 & 16.055 & 3.4415 \\
\hline A5 & 3040.4 & -4581.99 & 906.129 & 4266.7 & 169.968 & -3119.62 & 2.731 & 10.583 & 4.9298 \\
\hline A6 & 4243.9 & -3138.25 & 774.285 & 6714.2 & -200.492 & -3464.28 & 5.278 & 6.2773 & 5.7479 \\
\hline A7 & 5257.4 & -1922.46 & 1344.36 & 8426.1 & 519.968 & -4117.24 & 6.547 & 5.0463 & 5.7291 \\
\hline A8 & 5954.1 & -1086.61 & 251.128 & 12789 & -219.401 & -2252.15 & 13.81 & 1.7519 & 4.0425 \\
\hline
\end{tabular}

\section{Gibbs-Duhem Equation}

Further the partial molar quantity, activity and activity coefficient can also be determined by using Gibbs-Duhem equation ${ }^{22}$

$$
\begin{aligned}
& \sum x_{i} d z_{i}^{-M}=0 \\
& \text { or } \chi_{N A} d H_{N A}^{-M}+\chi_{S M} d H_{S M}^{-M}=0 \\
& \text { or } d H_{N A}^{-M}=\frac{\chi_{S M}}{\chi_{N A}} d H_{S M}^{-M} \\
& \text { or }\left[H_{N A}^{-M}\right]_{x_{N A}=y}=\int_{\chi_{N A}=y}^{\chi_{N A}=1} \frac{\chi_{S M}}{\chi_{N A}} d H_{S M}^{-M}
\end{aligned}
$$

Using equation (13) a graph (Fig. 1) between $\mathrm{H}^{-\mathrm{M}}$ sm and $\square \mathrm{SM} / \square$ SN gives the solution of the partial molar heat of mixing of a constituent NA in NA/SM solid dispersions and plot between lna SM $_{\text {vs }} \square \mathrm{SM} / \square_{\mathrm{SN}}$ determines the value of activity (Fig. 2) of component NA in binary mix.

\section{Interfacial Investigation}

The Solid-Liquid Interfacial Energy $(\sigma)$

It has been found that an experimentally observed value of interfacial energy ' $\sigma$ ' keeps a variation of 50$100 \%$ from one worker to other. However, Singh and Glickman $^{23}$ were calculated the solid-liquid interfacial energy $(\sigma)$ from melting enthalpy change and values obtained are found in good agreement with the experimental values. Turnbull empirical relationship ${ }^{24}$ between the interfacial energy and enthalpy change provides the clue to determine the interfacial energy value of solid dispersions and is expressed as:

$$
\sigma=\frac{C \Delta H}{(N)^{1 / 3}\left(V_{m}\right)^{2 / 3}}
$$

where the coefficient $\mathrm{C}$ lies between 0.33 to 0.35 for nonmetallic system, $\mathrm{Vm}$ is molar volume and $\mathrm{N}$ is the Avogadro's constant. The value of the solid-liquid interfacial energy of nicotinamide and sulphamerazine was found to be $5.05 \times 10^{-} 2$ and $4.68 \times 10^{-} 2 \mathrm{~J} \mathrm{~m}-2$ respectively and $\sigma$ value of solid dispersions was given in Table 1 .

\section{The Effective Entropy Change ( $\Delta \mathrm{Sv})$}

It is obvious that the effective entropy change and the volume fraction of phases in the alloy are interrelated to decide the interface morphology during solidification and the volume fraction of the two phases depends on the ratio of effective entropy change of the phases. The entropy of fusion $(\Delta \mathrm{S}=\Delta \mathrm{H} / \mathrm{T})$ value (Table 1) of binary solids is calculated by heat of fusion values of the materials. The effective entropy change per unit volume $\left(\Delta \mathrm{S}_{\mathrm{V}}\right)$ is given by

$$
\Delta S_{V}=\frac{\Delta H}{T} \cdot \frac{1}{V_{m}}
$$


Table 3: Value of partial and integral excess Gibbs free energy $\left(g^{E}\right)$, enthalpy $\left(h^{E}\right)$ and entropy( $\left(s^{E}\right)$ of NA-SM system

\begin{tabular}{|c|c|c|c|c|c|c|c|c|c|}
\hline Alloy & $\underset{\mathrm{J} / \mathrm{mol}}{\mathrm{g}_{\mathrm{NA}}}$ & $\underset{\mathrm{S} / \mathrm{mol}}{\mathrm{g}_{\mathrm{SM}}}$ & $\underset{\mathrm{J} / \mathrm{mol}}{\mathrm{gEl}^{\mathbf{E}}}$ & $\underset{\mathrm{J} / \mathrm{mol}}{\mathbf{h}_{\mathrm{NA}}}-\mathrm{E}$ & $\underset{\mathrm{S} / \mathrm{mol}}{\mathbf{h}_{\mathrm{SM}}}$ & $\begin{array}{c}\mathbf{h}^{\mathbf{E}} \\
\mathrm{J} / \mathrm{mol}\end{array}$ & $\underset{\mathrm{J} / \mathrm{mo} / \mathrm{K}}{\mathbf{s}_{\mathrm{AA}}}$ & $\underset{\mathrm{J} / \mathrm{mol} / \mathrm{K}}{\mathrm{S}_{\mathrm{SM}}}$ & $\underset{\mathrm{J} / \mathrm{mol} / \mathbf{K}}{\mathbf{S}^{\mathbf{E}}}$ \\
\hline $\mathrm{A} 1$ & 20.8553 & 3962.4 & 119.394 & 8708.718 & 1291540 & 40779.5 & 21.72 & 3218.94 & 101.65 \\
\hline E & 58.1069 & 1170.43 & 120.397 & -18392.9 & 79419.08 & -12915.5 & -46.255 & 196.161 & -32.68 \\
\hline A2 & 383.819 & 1130.24 & 432.337 & -19319.6 & 48764.74 & -14894.1 & -48.831 & 118.053 & -37.984 \\
\hline A3 & 1179.58 & 108.933 & 1056.46 & -15785.7 & 35288.38 & -9912.17 & -41.078 & 85.1803 & -26.558 \\
\hline A4 & 1511.32 & -383.26 & 1236.61 & -14867.4 & 23406.19 & -9317.71 & -39.343 & 57.145 & -25.353 \\
\hline A5 & 4266.7 & 169.968 & 3119.62 & -7940.51 & 6195.823 & -3982.34 & -27.188 & 13.4206 & -15.817 \\
\hline A6 & 6714.17 & -200.49 & 3464.28 & -8221.08 & -19328 & -13441.3 & -31.913 & -40.871 & -36.123 \\
\hline A7 & 8426.07 & 519.968 & 4117.24 & 17404.49 & -2964.14 & 6303.588 & 18.55 & -7.1986 & 4.51724 \\
\hline A8 & 12788.7 & -219.4 & 2252.15 & 153653.7 & 3300.25 & 31867.4 & 284.58 & 7.11041 & 59.8288 \\
\hline
\end{tabular}

Table 4: Value of volume free energy change change ( $\left.\square G_{\mathrm{v}}\right)$ during during solidificationfor NA-SM system at different undercoolings ( $\square$ T)

\begin{tabular}{lcccccc}
\hline Alloy & $\mathbf{1 . 0}$ & $\mathbf{1 . 5}$ & $\mathbf{2 . 0}$ & $\mathbf{G}_{\mathbf{v}} \mathbf{2 . 5}$ & $\mathbf{3 . 0}$ & \multicolumn{1}{c}{$\mathbf{3 . 5}$} \\
\hline A1 & 0.718 & 1.076 & 1.435 & 1.794 & 2.153 & 2.512 \\
E & 0.708 & 1.061 & 1.415 & 1.769 & 2.123 & 2.476 \\
A2 & 0.696 & 1.044 & 1.392 & 1.74 & 2.088 & 2.436 \\
A3 & 0.663 & 0.995 & 1.326 & 1.658 & 1.989 & 2.321 \\
A4 & 0.649 & 0.973 & 1.297 & 1.621 & 1.946 & 2.27 \\
A5 & 0.568 & 0.852 & 1.136 & 1.419 & 1.703 & 1.987 \\
A6 & 0.51 & 0.765 & 1.02 & 1.275 & 1.53 & 1.786 \\
A7 & 0.483 & 0.724 & 0.965 & 1.206 & 1.448 & 1.689 \\
A8 & 0.442 & 0.663 & 0.884 & 1.105 & 1.326 & 1.547 \\
NA & 0.726 & 1.089 & 1.452 & 1.815 & 2.178 & 2.541 \\
SM & 0.414 & 0.621 & 0.827 & 1.034 & 1.241 & 1.448 \\
\hline
\end{tabular}

Table 5: Critical size of nucleus ( $\left.\mathrm{r}^{*}\right)$ at different undercoolings $(\square \mathrm{T})$

\begin{tabular}{lcccccc}
\hline \multirow{2}{*}{ Alloy } & \multicolumn{5}{c}{$\mathbf{r}^{*}(\mathbf{n m})$} \\
& $\mathbf{1 . 0}$ & $\mathbf{1 . 5}$ & $\mathbf{2 . 0}$ & $\mathbf{2 . 5}$ & $\mathbf{3 . 0}$ & $\mathbf{3 . 5}$ \\
\hline A1 & 139.9 & 93.27 & 69.95 & 55.96 & 46.64 & 39.97 \\
E & 141.1 & 94.04 & 70.53 & 56.42 & 47.02 & 40.30 \\
A2 & 143.1 & 95.42 & 71.56 & 57.25 & 47.71 & 40.89 \\
A3 & 149.0 & 99.32 & 74.49 & 59.59 & 49.66 & 42.56 \\
A4 & 151.6 & 101.1 & 75.81 & 60.65 & 50.54 & 43.32 \\
A5 & 170.3 & 113.5 & 85.13 & 68.11 & 56.76 & 48.65 \\
A6 & 186.5 & 124.3 & 93.25 & 74.60 & 62.16 & 53.28 \\
A7 & 196.3 & 130.9 & 98.16 & 78.53 & 65.44 & 56.09 \\
A8 & 212.3 & 141.6 & 106.2 & 84.93 & 70.78 & 60.67 \\
NA & 139.0 & 92.66 & 69.49 & 55.60 & 46.33 & 39.71 \\
SM & 226.3 & 150.8 & 113.1 & 90.50 & 75.42 & 64.65 \\
\hline
\end{tabular}

Table 6: Value of critical free energy of nucleation ( $\left.\square G^{*}\right)$ for NA-SM system at different undercoolings $(\square T)$

\begin{tabular}{lllllll}
\hline \multirow{2}{*}{ Alloy } & $\mathbf{1 . 0}$ & $\mathbf{1 . 5}$ & $\mathbf{2 . 0}$ & $\mathbf{2 . 5}$ & $\mathbf{3 . 0}$ & \multicolumn{1}{c}{$\mathbf{3 . 5}$} \\
\hline A1 & 41.18 & 18.30 & 10.29 & 6.588 & 4.575 & 3.361 \\
E & 41.61 & 18.49 & 10.40 & 6.657 & 4.623 & 3.396 \\
A2 & 42.77 & 19.01 & 10.69 & 6.843 & 4.752 & 3.491 \\
A3 & 45.94 & 20.42 & 11.48 & 7.35 & 5.104 & 3.75 \\
A4 & 47.37 & 21.05 & 11.84 & 7.579 & 5.263 & 3.867 \\
A5 & 58.72 & 26.10 & 14.68 & 9.395 & 6.525 & 4.794 \\
A6 & 69.33 & 30.81 & 17.33 & 11.09 & 7.704 & 5.66 \\
A7 & 76.49 & 34.00 & 19.12 & 12.24 & 8.499 & 6.244 \\
A8 & 88.64 & 39.40 & 22.16 & 14.18 & 9.849 & 7.236 \\
NA & 40.85 & 18.15 & 10.21 & 6.536 & 4.539 & 3.335 \\
SM & 100.4 & 44.62 & 25.10 & 16.06 & 11.15 & 8.195 \\
\hline
\end{tabular}

where $\Delta \mathrm{H}$ is the enthalpy change, $\mathrm{T}$ is the melting temperature and $\mathrm{Vm}$ is the molar volume of solid phase. The entropy of fusion per unit volume $(\Delta \mathrm{SV})$ for NA and $\mathrm{SM}$ was found 726 and $414 \mathrm{kJK}^{-1} \mathrm{~m}^{-3}$ respectively. Values of $\Delta \mathrm{SV}$ for dispersed alloys are reported in Table 1 .

\section{The Driving Force of Nucleation $\left(\square G_{v}\right)$}

During growth of crystalline solid there is change in enthalpy, entropy and specific volume and nonequilibrium leads Gibb's energy. Thermodynamically metastable phase occurs in a supersaturated or supercooled liquid. The driving force for liquid-solid transition is the difference in Gibb's energy between the two phases. The theories of solidification process in past have
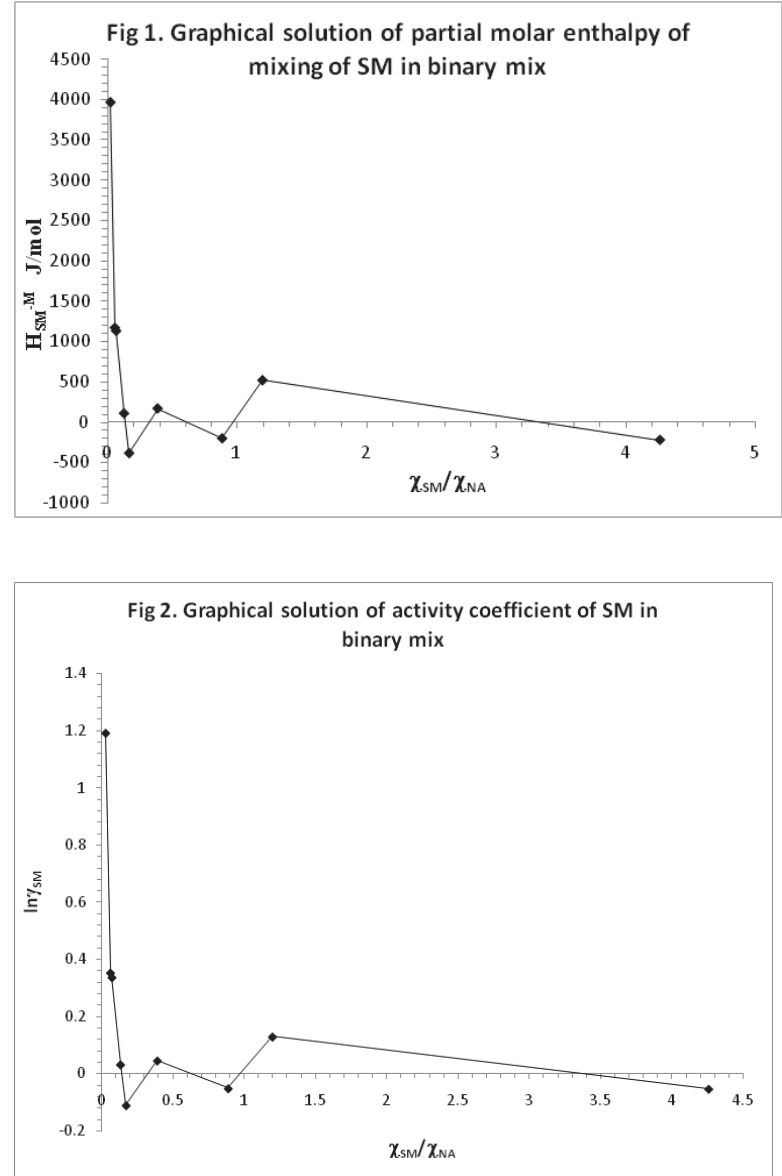

been discussed on the basis of diffusion model, kinetic characteristics of nucleation and on thermodynamic features. The lateral motion of rudementry steps in liquid advances stepwise/ non-uniform surface at low driving force while continuous and uniform surface advances at sufficiently high driving force. The driving force of nucleation/volume free energy change from liquid to solid during solidification $\left(\Delta G_{V}\right)$ can be determined at different undercoolings $(\Delta \mathrm{T})$ by using the following equation $^{25}$

$\left.\Delta G_{V}\right)=\Delta \mathrm{Sv} \Delta \mathrm{T}$

It is opposed by the increase in surface free energy due to creation of a new solid-liquid interface. By assuming that solid phase nucleates as small spherical cluster of radius arising due to random motion of atoms within liquid. The value of $\Delta \mathrm{G}_{\mathrm{V}}$ for solid dispersions and pure components are shown in the Table 4. 


\section{The Critical Radius $\left(r^{*}\right)$}

During liquid-solid transformation embryos are rapidly dispersed in unsaturated liquid and on undercooling liquid becomes saturated and provide embryo of a critical size with radius $\mathrm{r}^{*}$ for nucleation which can be expressed by the Chadwick relation ${ }^{26}$

$$
r^{*}=\frac{2 \sigma}{\Delta G_{V}}=\frac{2 \sigma T}{\Delta H_{V} \Delta T}
$$

where $\sigma$ is the interfacial energy and $\Delta \mathrm{H}_{\mathrm{V}}$ is the enthalpy of fusion of the compound per unit volume, respectively. The critical size of the nucleus for the components and alloys was calculated at different undercoolings and values are presented in Table 5 which lies between $39.71-226.3 \mathrm{~nm}$. It can be inferred from table that the size of the critical nucleus decreases with increase in the undercooling of the melt. The existence of embryo and a range of embryo size can be expected in the liquid at any temperature.

\section{Critical Free Energy of Nucleation $\left(\Delta \mathbf{G}^{*}\right)$}

To form critical nucleus, it requires a localized critical free energy of nucleation $\left(\Delta \mathrm{G}^{*}\right)$ which is evaluated ${ }^{27}$ as

$$
\Delta G^{*}=\frac{16}{3} \frac{\pi \sigma^{3}}{\Delta G_{v}^{2}}
$$

The value of $\Delta \mathrm{G}^{*}$ for alloys and pure components has been found in the range of $10^{-15}$ to $10^{-16} \mathrm{~J}$ per molecule at different undercoolings, and has been reported in Table 6 .

\section{Gibbs-Thomson Coefficient ( $\tau$ )}

For a planar grain boundary on planar solid-liquid interface the Gibbs-Thomson coefficient $(\tau)$ for the system can be calculated by the Gibbs-Thomson equation is expressed as;

$$
\tau=r \Delta T=\frac{T V_{m} \sigma}{\Delta H}=\frac{\sigma}{\Delta S_{V}}
$$

where $\tau$ is the Gibbs-Thomson coefficient, $\Delta \mathrm{T}$ is the dispersion in equilibrium temperature and, $r$ is the radius of grooves of interface. The theoretical basis of determination of $\tau$ was made for considering equal thermal conductivities of solid and liquid phases for some transparent materials. It was also determined by the help of Gunduz and Hunt numerical method ${ }^{28}$ for materials having known grain boundary shape, temperature gradient in solid and the ratio of thermal conductivity of the equilibrated liquid phases to solid phase $(\mathrm{R}=\mathrm{KL} / \mathrm{KS})$. The Gibbs-Thomson coefficient for NA, SM and their solid dispersions are found in the range of $1.34-2.19 \times 10-{ }^{05} \mathrm{Km}$ and is reported in Table 1.

\section{Interfacial Grain Boundary Energy ( $\square$ gb)}

Grain boundary is the internal surface which can be understood in a very similar way to nucleation on surfaces in liquid-solid transformation. In past, a numerical method ${ }^{29}$ was applied to observe the interfacial grain boundary energy $(\sigma g b)$ without applying the temperature gradient for the grain boundary groove shape. For isotropic interface there is no difference in the value of interfacial tension and interfacial energy. A considerable force is employed at the grain boundary groove in anisotropic interface. The grain boundary energy can be obtained by the equation:

$$
\sigma_{g b}=2 \sigma \cos \theta
$$

where $\theta$ is equilibrium contact angle precipitates at solidliquid interface of grain boundary. The grain boundary energy could be twice the solid-liquid interfacial energy in the case where the contact angle tends to zero. The value of $\sigma_{\mathrm{gb}}$ for solid NA and SM was found to be 9.75 x $10-^{2}$ and $9.04 \square 10-{ }^{2} \mathrm{Jm}_{-}^{2}$ respectively and the value for all solid dispersions is given in Table 1 .

\section{Interface Morphology}

The science of growth has been developed on the foundation of thermodynamics, kinetics, fluid dynamics, crystal structures and interfacial sciences. The solidliquid interface morphology can be predicted from the value of the entropy of fusion. According to Hunt and Jackson ${ }^{30}$, the type of growth from a binary melt depends upon a factor $\alpha$, defined as:

$$
\alpha=\xi \frac{\Delta H}{R T}=\xi \frac{\Delta S}{R}
$$

where $\xi$ is a crystallographic factor depending upon the geometry of the molecules and has a value less than or equal to one. $\Delta \mathrm{S} / \mathrm{R}$ (also known as Jackson's roughness parameter $\alpha$ ) is the entropy of fusion (dimensionless) and $\mathrm{R}$ is the gas constant. When $\alpha$ is less than two the solid-liquid interface is atomically rough and exhibits non-faceted growth. The value of Jackson's roughness parameter $(\Delta \mathrm{S} / \mathrm{R})$ is given in Table 1 . For the entire solid dispersions the $\square$ value was found greater than 2 which indicate the faceted ${ }^{31}$ growth proceeds in all the cases.

\section{CONCLUSION}

The solid-liquid equilibrium data of NA-SM system show the formation of simple eutectic. The activity and activity coefficient values determined by using heat of fusion data are very useful in computing thermodynamics of mixing and excess functions. Thermodynamic excess and mixing functions $\mathrm{g}^{\mathrm{E}}$ for all solid dispersions and $\square \mathrm{GM}^{\mathrm{M}}$ values for eutectic and non-eutectic solid dispersions A5-A8 have been found positive which suggest the stronger association between like molecules and there is non-spontaneous mixing in the binary dispersed alloys. The negative value of $\Delta \mathrm{G}^{\mathrm{M}}$ for E and A1-A4 favours the spontaneous mixing in these cases. The critical radius of all the solid dispersions at different undercoolings has been found in nano-scale. The value of Jackson's roughness parameter $(\alpha)$ for all solid dispersions was found greater than 2 which suggest the faceted growth proceeds in all the cases. 


\section{ACKNOWLEDGEMENT}

Thanks are due to the Head Department of Chemistry, V K S University Ara 802301, India for providing research facilities.

\section{REFERENCES}

1. Murrey, M. F. and Srinivasan, A. 1995. Biochem. Biophys. Res. Commun. 210: 954-959.

2. Murrey, M. F. 2003. Clinical infectious Diseases, 36: 453-460.

3. Niren, N. M. 2006. Cutis. 77: 11-16.

4. Girgis, A. S., Hosni, H. M. and Barsoum, F. F. 2006. Bioorganic \& Medicinal Chemistry. 14(13): 4466-4476.

5. Gutsell, J. S. and Snieszko, S. F. 1949. Transactions of the American Fisheries Society. 76(1): 82-96.

6. Sneader, W. 2005. Drug discovery: a history, wiley press, England.

7. Del, S. R., Lazzoi, M. R. and Vasapollo, G. 2010. Drug Deliv.17(3): 130-137.

8. Bryn, S. R., Xu, W. and Newman, A. W. 2001. Adv. Drug Del. Rev. 48:115-136.

9. Remenar, J. F. et al. 2003. J. Am. Chem. Soc. 125: 8456-8457.

10. Good, D. J. and Guez-Hornedo, N. R. 2009. Cryst Growth Dev. 9: 2252-64.

11. Shiraki, K. et al. 2008. Pharm. Res. 25: 2581-92.

12. Ansari, M. T. et al. 2012. Pak. J. Pharm. Sci. 25(2): 447-456.

13. Aggarwal, A. K., and Jain, S. 2011. Chem. Pharm. Bull. 59(5): 629638

14. Sangster, J. 1999. J. Phy. Chem. Ref. Data. 28: 889-930.
15. Sekiguchi, K. et al. 1969. Chem. Pharm. Bull. 17: 191.

16. Shekhar, H., Pandey, K. B. and Kant, V. 2012. Int. J. Chemistry. 1(2): 257-263.

17. Rambaud, J., et al. 1986. Farmaco Ed. Prat. 41: 889.

18. Malaviolle, R. et al. 1988. Thermochemi. Acta. 121: 283.

19. Shekhar, H. and Salim, S. S. 2011. J. Nat. Acad. Sci Letter. 34: 117125 .

20. Nieto, R., Gonozalez, M. C. and Herrero, F. 1999. American Journal of Physics. 67: 1096-1099.

21. Agrwal, T. et al. 2010. J. Chem. Engg. Data. 55: 4206-4210.

22. Shamsuddin, M., Singh, S. B. and Nasar, A. 1998. Thermochemica Acta. 316: 11-19.

23. Singh, N. B. and Glicksman, M. E. 1989. J. Cryst. Growth. 98: 573580 .

24. Turnbull, D. 1950. J. Chem. Phys. 18: 768.

25. Hunt, J. D. and Lu, S. Z. 1994. Hand Book of Crystal Growth Ed. DTJ Hurle, Elsevier, Amsterdam, 112.

26. Chadwick, G. A. 1972. Metallography of Phase Transformation, Butterworths, London, 61.

27. Wilcox, W. R. 1974. J. of crystal growth. 26: 153-154.

28. Gunduz, M., Hunt, J. D. 1989. Acta Metall. 37: 1839.

29. Akbulut, S., Ocak, Y., Keslioglu, K. and Marasli, N. 2009. Applied Surface Science. pp: 3594-3599.

30. Hunt, J. D. and Jackson, K. A. 1966. Trans. Metall. Soc. AIME. 236: 843.

31. Shekhar, H. and Kant, V. 2011. I. J. Chem. Soc. 88: 947-952. 